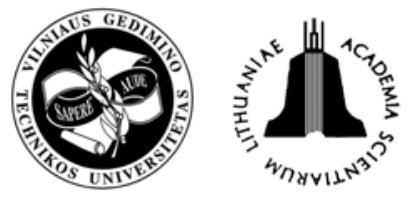

\title{
A SOIL LOOSENING MACHINE FOR WINTER EARTH-MOVING IN TRANSPORT CONSTRUCTION
}

\author{
Ivan Dyakov, Valeriy Ivkin, Alexey Popovich \\ Dept of Foundations of Car Designing and Construction, Ulyanovsk State Technical University, \\ Severny Venetz Str. 32, 432027 Ulyanovsk, Russia \\ E-mail:i.dyakov@ulstu.ru
}

Received 23 April 2007; accepted 10 September 2007

\begin{abstract}
The main methods of frozen soil loosening are considered from the perspective of their effectiveness in transport-related construction, and a new type of equipment is offered for earth-moving in winter conditions.
\end{abstract}

Keywords: frozen soil, power intensity of breaking, gasodynamic effect, mechanical action, loosening machine.

\section{Introduction}

The share of earth-moving in the construction work is considerable, with frozen soil excavation making $20 \%$ of annual earth-moving in Russia. The cost of frozen soil digging equals the cost of all other earth-moving works (related to not frozen soil). The main characteristic of frozen soil is its low temperature. Solid mineral particles of not frozen soil, which are not firmly stuck together, are cemented by ice at low temperatures, making a hard and solid monolith. This soil cannot be excavated by commonly used earth-moving equipment (e. g. bulldozers, scrapers, excavators, motor graders, etc.).

Preliminary loosening of such soils can be made by special building machines known as rippers. Various methods of loosening frozen soils are used in construction. Their power intensity and labour input required are given in Table 1.

Most labour-consuming and unprofitable methods are those involving unfreezing of frozen soil by steam, hot water or using electric appliances, as well as by thermochemical and fire heating.

\section{Soil loosening machines}

Impact machines, depending on the way of applying the impact momentum to the soil which is broken down, can have a falling element (wedge) or an element, supported on the ground (a driven wedge).

In the first case, the impact momentum is created by the kinetic energy of the tool's mass, while, in the second case, it is provided by the kinetic energy of the falling weight (of the impact element).

Machines with the falling elements are most widely used. This may be accounted for by the simplicity of their design. However, their main disadvantage is that the dynamic loads arising when massive tools are falling freely
Table 1. Power intensity and labour consumption of frozen soil loosening

\begin{tabular}{|c|c|c|}
\hline $\begin{array}{l}\text { Methods of frozen soil } \\
\text { loosening }\end{array}$ & $\begin{array}{c}\text { Power } \\
\text { intensity, } \\
\mathrm{kW} \cdot \mathrm{h} / \mathrm{m}^{3}\end{array}$ & $\begin{array}{c}\text { Labour } \\
\text { consumption, } \\
\text { man-day } / \mathrm{m}^{3}\end{array}$ \\
\hline $\begin{array}{l}\text { Unfreezing: } \\
\text { - by fire; } \\
\text { - by steam and hot water; } \\
\text { - by electric heater }\end{array}$ & $\begin{array}{c}136 \\
190 \\
81\end{array}$ & $\begin{array}{c}0.11-0.14 \\
0.16 \\
0.28-0.7 \\
\end{array}$ \\
\hline $\begin{array}{l}\text { Loosening by drilling and } \\
\text { blasting }\end{array}$ & 1.4 & 0.048 \\
\hline $\begin{array}{l}\text { Mechanical methods: } \\
\text { - cutting; } \\
\text { - impact breaking; } \\
\text { - vibration loosening }\end{array}$ & $\begin{array}{l}5.4 \\
0.55 \\
1.64\end{array}$ & $\begin{array}{l}0.003-0.09 \\
0.005-0.05 \\
0.044-0.08\end{array}$ \\
\hline Manual loosening & - & 1.9 \\
\hline $\begin{array}{l}\text { Soil loosening by } \\
\text { gasodynamic loosening } \\
\text { machines }\end{array}$ & 0.4 & $0.005-0.05$ \\
\hline
\end{tabular}

and striking against the surface of the ground cause cracking of metal elements of the structure, bending of the slides, breaking of separate units and elements, fastening them to tractors, and wearing of friction-drive winches.

Machines with the working element supported on the ground are not widely used. This is because compact, reliable and strong impact elements (parts) capable of providing a powerful stroke required for breaking up frozen soil have not been developed yet.

At the same time, machines with driving wedges have a number of advantages. They can make a central impact and can use an additional static load to increase the breaking effect on frozen soil. 
Usually, machines of this type are installations based on tractors and excavators equipped with diesel hammers. Their main disadvantage is that diesel hammers are not reliable and efficient at low temperature. Loosening of frozen soils by vibrating tools is not widely used in practice.

\section{Experimental results}

Testing of prototype machines of the described type has shown that they cannot deliver a powerful blow and, therefore, may be only used for loosening weak sand and sand loam soils.

A method of soil cutting is much wider used for earth-moving in winter conditions.

This may be accounted for by long-term experience of cutting rock in mining industry and the possibility to use working parts of coal-miners of series production for this purpose.

A significant disadvantage of these machines is heavy wearing of their cutting elements (cutters or teeth) because frozen soil is highly abrasive in excavating.

The most simple, reliable and effective machines ensuring effective continuous breaking of frozen soil are mounted rippers of static action.

A ripper consists of a welded metal frame and a working part in the form of a tooth with a straight post and cast (removable) cutter point. The hydraulic control allows its positive penetration.

Static-type rippers can be effectively used for loosening frozen soil, when the traction force of the main machines is at least 15-20 t. This can be provided by trucktractors with the power in the range of $150-300 \mathrm{~kW}$ and upwards, and the efficiency of loosening frozen soil reaching $80-150 \mathrm{~m}^{3} / \mathrm{h}$.

Machines based on mechanical methods of frozen soil loosening are most widely used in separate earth-moving operations with small bulk up of the soil, performed under difficult conditions of transport construction. Great attention is paid to their development and improvement. However, most of these machines do not always meet the requirements of construction in the above conditions and have the following disadvantages: high power consumption, low reliability, heavy wear of working parts, poor manoeuvrability and narrow specialization.

It is hardly possible to solve the problem of increasing the volume of frozen soil loosening work in difficult conditions of construction in transport area only by choosing a rational design and operating parameters of the existing machines and increasing their power to weight ratio. Actually, it is necessary to design tools based on new effective methods of loosening frozen soils.

Technical and economic indicators of the existing soil loosening machines can be improved by activating their working parts, i. e. by transferring some additional power to them.

To increase the effectiveness of frozen soil loosening methods, earth-moving machines should be equipped with the most perspective and practical gas-impulse equipment.
Small size and weight as well as simplicity of design and high power to weight ratio of earth-moving machines with gas-impulse intensifiers allow them to increase productivity and reduce specific consumption of materials compared to these parameters of others commonly used machines.

For loosening soil by the above methods, pneumatic-tyred truck tractors or excavators of small and medium power, not widely used in winter conditions through their transportation qualities are high, can be employed (see Fig. 1).

Researchers, studying the compaction deformation of frozen soils, found that soil compaction is a complicated physical and mechanical process caused, in this case, by deformation and displacement of all soil components, including gaseous, liquid (e. g. not frozen water at temperature up to $-70{ }^{\circ} \mathrm{C}$ ), ice and solid mineral particles [1].

Since the bonds between soil particles are much weaker than those between mineral particles, the cementing bounds of ice-cement are broken, while mineral particles are rearranged and displaced from a more highly stressed zone to the bulk of unbroken soil in the process of compaction.

This causes changes in soil volume as well as reduction of its porosity, i. e. compaction.

Recently, methods of frozen soil breaking based on the dynamic action of breaking load on the soil, allowing

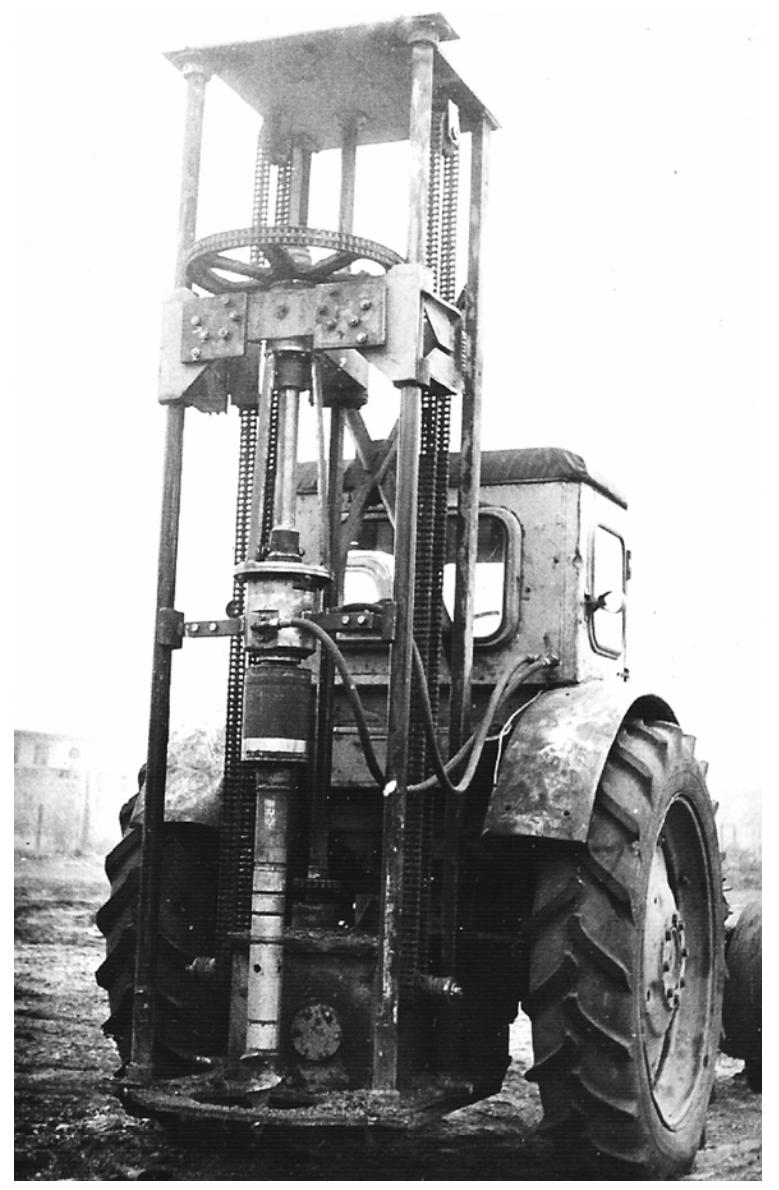

Fig. 1. Standard working equipment of gasodynamic soil loosening machine 
the impacts of tremendous power capable of breaking down frozen soils of actually any strength to be developed, have become popular. High efficiency of breaking is obtained due to the fact that, at a high rate of loading, the soil mass is broken as a brittle solid, with the process of cracking being dominant. In this process, the working element, which may be either solid (a wedge) or gaseous (high-pressure gas) acts on the edges of the major cracks, causing them to grow.

Since the initial moment of interaction between the soil and the tool, corresponding to the origination and propagation of cracks, is the most power intensive phase of the process, while crack development requires less effort. Therefore, the expansion of the compressed gas leads to wedging out of cracks, and intensifying of cracking, thereby determining low power intensity of breaking [2-6].

When soil is loosening by gasodynamic soil loosening machines, two work stages may be distinguished:

- stage 1 - screwing the soil loosening machine down to the specified depth of loosening with simultaneous filling of the working chamber with highly compressed air;

- stage 2 - loosening the soil with compressed air.

The process of driving the equipment to a specified depth of ripping is taking advantage of frozen soil capacity to consolidate by eliminating voids between the particles and breaking down the cementing ice. However, the displaced soil is not broken down and transported to the surface of the ground. The tool cuts a screw thread in the

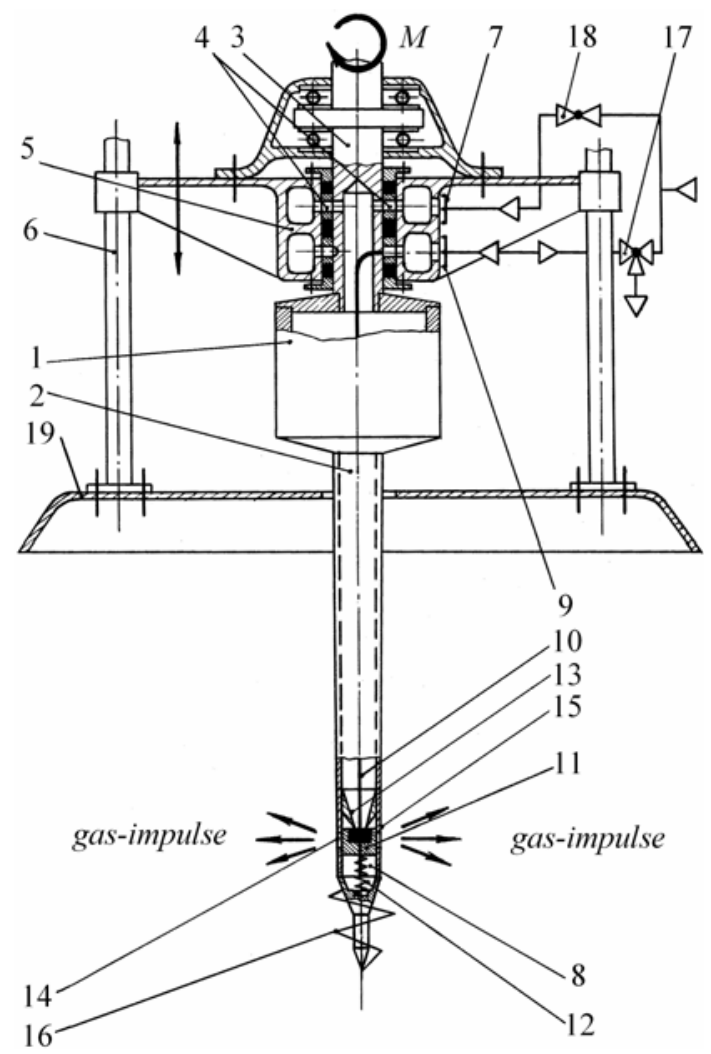

Fig. 2. A schematic view of gasodynamic soil loosening machine frozen soil, while the soil consolidates and is pressed out into the virgin soil mass.

The operating tool is wrung out by the soil moved apart in screwing it down, thus creating the pressure sufficient to effectively break up frozen soil, when the working chamber is discharged. Effective breaking is achieved due to the combined effect on the medium, including the mechanical effect creating the stressed state and causing crack initiation in the area of the exhaust ports, occurring when the ripper is being screwed down in the soil, and the pneumatic effect caused by the action of gases going out from the exhaust ports made by the ripper. The gases flow into the formed cracks, wedging them out and causing the separation of a certain amount of soil from its mass [2-6].

The structural soil loosening machine design is demonstrated in Fig. 2. The working chamber 1 is connected to the rod 2, whose internal space is integral with the working chamber. The internal space of the shank 3 is also the extension of the working chamber 1 . The shank 3 is connected to the driving mechanism.

The unit 5 of gas distribution, moving along the slides 6 , allows the working chamber 1 and the control chamber 8 to be separately filled with compressed air and separately discharged.

When the cock 18 is open, the compressed air goes to the working chamber 1 through the connection point 7 and radial openings 4 in the shank 3 .

The compressed air gets to the control chamber 8 through the connection point 9 and the tube 10, when the control cock 18 is opened.

The valve mechanism, consisting of the valve 11 , the spring 12 and the valve seat 13 , control air outlet through the exhaust ports 14 found on the discharge bush 15 .

The valve is normally closed, separating the control chamber 8 from the working chamber 1 . The valves of this type are usually controlled by the power of the compressed air.

At the first stage of the soil loosening's operation, the operator installs the equipment in place, turns on the driving mechanism and the screw blade 16 starts screwing in the soil. The operator also opens the control cocks 17 and 18, allowing the air to go separately to the control chamber 8 and the working chamber 1 . Pressure in these chambers is controlled by the operator according to the indication of manometers, which are not shown in Fig. 2.

When the soil loosening machine is screwed in the ground to the specified depth, the second stage, i. e. soil loosening, begins.

At this stage, the operator turns the control cock handle 17 so that the control chamber 8 is communicated with the atmosphere. The pressure in the chamber falls, while the valve 11 is shifted downward due to the pressure difference, opening the exhaust ports 14 . The air flows out of the exhaust ports at a high rate, thereby loosening the soil. The symmetric arrangement of the exhaust ports on the discharge bush at the right angle to the tool's axis prevents from the occurrence of the reaction force, when the working chamber is discharged.

The protective screen 19 ensures safe operation, preventing from scattering of the soil particles. When 
Table 2. Technical characteristics of high-pressure compressors

\begin{tabular}{|l|c|c|c|c|c|c|c|}
\hline \multirow{2}{*}{$\begin{array}{c}\text { Type of compressor } \\
\text { (in Russian alphabet) }\end{array}$} & \multirow{2}{*}{$\begin{array}{c}\text { Delivery } \\
\text { capacity, l/min }\end{array}$} & \multirow{2}{*}{$\begin{array}{c}\text { Delivery } \\
\text { pressure, MPa }\end{array}$} & \multirow{2}{*}{$\begin{array}{c}\text { Power } \\
\text { consumption, } \mathrm{kW}\end{array}$} & \multicolumn{3}{|c|}{ Overall dimensions, mm } & \multirow{2}{*}{ Mass, kg } \\
\cline { 5 - 8 } КВД-1.6 & 2.2 & 15.0 & 8.0 & 580 & 310 & 710 & 170 \\
\hline ДК-200 & 2.0 & 20.0 & 8.0 & 430 & 450 & 490 & 85 \\
\hline 1 К & 8.0 & 20.0 & 26.0 & 885 & 825 & 1295 & 700 \\
\hline К-5 & 16.0 & 22.5 & 50.0 & 1200 & 1080 & 1820 & 1350 \\
\hline К-6 & 8.0 & 22.5 & 35.0 & 850 & 580 & 1355 & 600 \\
\hline К-7 & 6.5 & 22.5 & 26.0 & 832 & 585 & 1000 & 445 \\
\hline ДК-2 & 8.0 & 23.0 & 47.0 & 2200 & 890 & 860 & 820 \\
\hline ДК-10 & 9.0 & 40.0 & 96.0 & 2200 & 890 & 860 & 820 \\
\hline ЭК-15-1М & 16.0 & 20.0 & 42.0 & 1185 & 860 & 1535 & 1200 \\
\hline
\end{tabular}

pressure in the chamber 1 falls, the spring 12 returns the valve 11 in its normally closed state. The cocks 17 and 18 are closed, while the working equipment is removed and placed on the new site, where the cycle of soil loosening operation is repeated. When choosing a source of compressed gas supply, reliable and efficient compressor plants of small mass should be preferred (see Table 2).

The depth of soil loosening for a new machine is determined depending on the soil strength characteristics and gas-impulse power. In its turn, gas-impulse power is the work performed by the compressed gas in the time unit during its adiabatic flow out of the working chamber:

$$
N_{\text {gas }}=\frac{A_{\text {gas }}}{t_{\text {flow }}},
$$

where $N_{g a s}$ is the gas-impulse power; $A_{g a s}$ is the work performed by the compressed gas; $t_{\text {flow }}$ is time unit of process.

The work performed by the compressed air in its adiabatic flow is calculated by a well-known formula of gas mechanics as follows:

$$
A_{g a s}=\frac{P \cdot V}{K-1} \cdot\left(1-\left(\frac{P_{1}}{P}\right)^{\frac{K-1}{K}}\right) \text {, }
$$

where $P$ is the compressed air pressure; $P_{1}$ is the ultimate pressure of the expanding gas; $V$ is the volume of the working chamber; $K=1.41$ is adiabatic path indicator.

\section{Conclusions}

A distinctive feature of new equipment is that the least power-consuming method of forcing it in the soil screwing is used. In this case, frozen soil is broken down by the power of highly compressed air [2-6] supplied by a high-pressure compressor.

The major preconditions for effective use of new equipment for winter earth-moving in transport-related construction are as follows:

1. The breaking of the soil proceeds deep in its mass, where the strength is lower, rather than on the surface, where the strength of the soil is maximum.

2. The power of the compressed air is directly transferred to the soil being broken, which may be considered a material acted upon by gas impulse. Frozen soil is broken down in all possible directions of the compressed air expansion. This helps the machines considered to achieve higher quality of breaking, compared to that obtained by impact-based machines and static rippers, because the movement of the working tools of the latter in frozen soil is strictly restrained.

3. More effective operation in the period, when a thaw has set in, and frozen soil starts thawing, while there still is a layer of frozen soil under the unevenly thawing ground, is achieved because the impact power of the impact-based machines is partially or completely dampened by a thawing soil layer.

Breaking of soil by the compressed gas power directly transferred to the working tool (passing the engine) is associated with changes in the machine design.

This method of soil loosening provides the possibility to transfer large breaking power to the working tool without considerably increasing mass and efficiency of the main machine.

\section{References}

1. CYTOVICH, N. Frozen ground mechanics (ЦЫТОВИЧ, Н. А. Механика мёрзлых грунтов). Moscow: High school, 1973. 448 p. (in Russian).

2. IVKIN, V. Patent No 2209891 RU, MPK7 E 02 F 5/32 Gas-dynamic loosen machine, UISTU, No 2002110492/03; declared 19.04.02, published 10.08.03, No 22.12 p. (in Russian).

3. SHELIKALIN, V., IVKIN, V. Patent No $2231601 R U$, MPK7 E 02 F5 /30 Gas-dynamic loosen machine, UISTU, declared 25.03.03, published 27.06.04, No 18. 16 p. (in Russian).

4. KUZMIN, E., IVKIN, V. Patent No 2236514 RU, MPK7 E 02 F5 / 32 Gas-dynamic loosen machine, UISTU, declared 03.06.03; published 20.09.04, No 26. 15 p. (in Russian).

5. MOROZOV, V., IVKIN, V. Patent No 2252989 RU, MPK7 E 02 F5 / 32 Device for destruction of durable and frozen ground, UlSTU, declared 02.03.04; published 27.05.05, No 15.12 p. (in Russian).

6. MOROZOV, V., IVKIN, V. Patent No 2276235 RU, MPK7 E 02 F5 / 30 Device for destruction of durable and frozen ground, UISTU, declared 21.06.04; published 10.05.06, No 13. 21 p. (in Russian). 